\title{
Effect of Majoon Murmakki in Dysmenorrhoea (Usre Tams): A Standard Controlled Clinical Study
}

\section{Habiba Suhail' ${ }^{1}$ Kouser Fathima Firdose ${ }^{2}$, Wajeeha Begum ${ }^{3}$, Mirza Belal Beg ${ }^{4}$}

Section: Healthcare

Sci. Journal Impact

Factor: $6.1(2018)$

ICV: 90.90 (2018)

(c) (7) (8)

Copyright@IJCRR
'PG Scholar, Department of 11 mul Qabalat wa Amraze Niswan, NIUM, RGUHS, Bangalore, India; 'Lecturer, Department of 1 lmul Qabalat

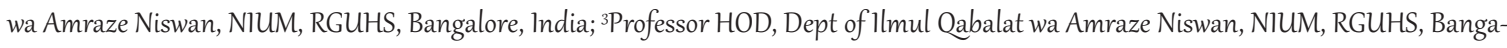
lore, India; 4 PG Scholar Department of Ilmul Advia (Pharmacology) CRIUM Hyderabad, India.

\section{ABSTRACT}

Background: Dysmenorrhoea is a condition characterised by severe uterine pain during menstruation with a prevalence range between 50 to $87.8 \%$. Many drugs have been tried to alleviate dysmenorrhea in women, but adverse events occur, therefore investigation of alternative treatments for dysmenorrhoea is warranted. The objective of this study is to compare the effect of Majoon Murmakki in dysmenorrhoea (usre tams).

Materials and Methods: In a randomised standard controlled study, 45 patients of dysmenorrhea were randomly assigned to test $(n=30)$ and control group $(n=15)$. In test Majoon Murrmakki $3 g m$ and control group mefenamic acid $500 m g$ two times a day was given orally from 1 st to 5 th days of menstruation for two consecutive cycles. The primary outcome was assessed by subjective parameters viz. pain abdomen, nausea, vomiting, low backache diarrhoea fatigue and secondary outcome assessed by objective parameters viz. visual analogue scale for pain were assessed at each follow-up and improvement in the quality of life were assessed by SF-12 questionnaire before and after treatment.

Results: Significant relief was observed in dysmenorrhoea and associated symptoms. $26(89.7 \%)$ of the patients in test and $13(100 \%)$ in the control group were relieved with $p<0.001$ in subjective parameters as the primary outcome. $26(89.7 \%)$ of the patients in test and $13(100 \%)$ in the control group were relieved with $p<0.001$ in objective parameters as the secondary outcome. Intergroup comparison shows no significant difference in improving subjective and objective parameters with $p=1.00$ and $\mathrm{p}=0.540$ respectively.

Conclusion: Majoon Murmakki is as effective as mefenamic acid in alleviating dysmenorrhea and associated symptoms.

Key Words: Usre tams, Dysmenorrhea, Majoon Murmakki, SF 12 questionnaire, Visual analogue scale

\section{INTRODUCTION}

Dysmenorrhoea is defined as the occurrence of painful cramps of uterine origin during menses and is one of the most common causes of pelvic pain which affects the quality of life of women in their reproductive age, ${ }^{1}$ often accompanied by other biological symptoms including dizziness, fatigue, backache, headache, vomiting and diarrhoea all occurring just before or during the menstruation ${ }^{2}$ It may involve various types of pain, and may also precede menstruation for several days or occur during menstruation. ${ }^{3}$ It has a high prevalence of worldwide ${ }^{4}$ and affects the majority of women of reproductive age with $2-29 \%$ having severe pain. ${ }^{5}$. Dysmenorrhoea represent a substantial public health burden, ${ }^{4}$ that exceeds all other gynaecologic complaints ${ }^{1}$ and is one of the leading cause of absenteeism from school and work, loss of earnings and diminished QoL but still, it is undertreated. ${ }^{1,4}$

Dysmenorrhoea is conventionally treated with NSAIDs or oral contraceptive pills, the efficacy of which is supported by research evidence, however NSAIDs and OCPs have limitations; some women with dysmenorrhoea do not respond to NSAIDs and OCPs (with an estimated failure rate of $>15 \%$ for NSAIDs); some cannot use these medications because of contraindication or adverse effects, some prefer not to use any medication. Therefore, investigation of complementary alternative treatments for dysmenorrhoea is warranted. Better management of dysmenorrhoea may not only improve women's quality of life but also reduce their risk of developing future pain. ${ }^{6}$

\section{Corresponding Author:}

Dr. Kouser Fathima Firdose, Lecturer, Department of IImul Qabalat wa Amraze Niswan, NIUM, RGUHS, Bangalore, India. Email: kouser2fathima@gmail.com

ISSN: 2231-2196 (Print)

Received: 13.06 .2020
ISSN: 0975-5241 (Online)

Revised: 24.08 .2020
Accepted: 17.10 .2020 
Unani medicine plays an important role in treating various gynaecological disease, of which drugs like habbul ghar, qust, zarawand, irsa, ${ }^{7}$ turbud, rewand khatayi, hulba, post fali amaltas, jawtri, ${ }^{8,9}$ ma 'jūnmusakkin dard al-rahim, jawārish $a_{m b e r}{ }^{8}$ have been mentioned for the treatment of dysmenorrhea, of these Murmakki has been selected for the treatment of dysmenorrhoea in the present study. By thorough review of Unani literature, murmakki was found to have the properties like musakkin awjāh (analgesic), muhallil awram (antiinflammatory), mudirr-i-bowl wa hayd(diuretic and emmenagogue), mufattih sudad (deobstruent) among others. ${ }^{10}$

Besides, recent studies show that furanose squiterpenes with analgesic activity such as furanoelemanes, furanoeudesmanes and furanogermacranes, are present in the gum resin extract of myrrh ${ }^{11}$ With all these properties murr is anticipated to alleviate dysmenorrhoea and hence selected for the present study.

\section{MATERIAL AND METHODS}

This study was conducted in the department of Ilmul Qabalat wa Amraze Niswan, NIUM, Bengaluru from May 2019 to February 2020.

Ethical clearance and CTRI registration number: The institutional ethical committee approved the present study [IEC No: NIUM/IEC/2017-18/010/ANQ/02]; following which CTRI registration was accomplished vide number CTRI/2011/04/018446.After which the clinical study was carried out.

Study design: Single-blind randomized standard controlled trial.

Duration of study: One and a half year.

Sample size: 45

- The sample size was calculated using formula $\mathrm{N}=2\left[(\mathrm{Z} \alpha-Z \beta) \sigma \mid \mu_{1}-\mu_{2}\right]^{12}$

\section{Method of collection of data:}

- History Taking \& Clinical examination

\section{Inclusion criteria:}

- Patients in the age group of $18-35$ years ${ }^{13}$ with regular painful menstrual cycles i.e. 21-35 days with one or more associated symptoms like nausea, vomiting, low backache, diarrhoea, fatigue ${ }^{14} \&$ VAS score $>7$

\section{Exclusion criteria:}

- Systemic Illness like HTN/ DM, \& H/o allergy /sensitive to NSAIDs, hormonal treatment last 2 months

- Lactating women

Treatment was subsequently started inpatient fulfilling the inclusion criteria. The test or control drug as randomised was given for 5 days from the first day of the menstrual cycle for two consecutive cycles. Assessment of subjective and objective parameters was done before, during and after treatment. Liver function test (LFT) \& renal function test (RFT) were assessed pre and post-treatment for assessment of safety

Subjective parameters studied were pain abdomen, nausea, vomiting, low Backache, fatigue, diarrhoea and objective parameters were visual analogue scale (VAS) for pain \& SF-12 scale for quality of life.

Test drug: Murmakki (Commiphora myrrha) was purchased from the local market and identified by the chief pharmacist of NIUM Bengaluru. Ma'jūn was prepared with honey according to the standard method of preparation.

Dosage: 3 gm twice a day, orally

Standard control: Mefenamic acid $500 \mathrm{mg}$ twice a day

Duration of treatment: from $1^{\text {st }}$ to $5^{\text {th }}$ days of menstruation for 2 consecutive cycles

\section{Outcome measure:}

\section{Primary outcome measure:}

Relieved: Relief in $\geq 3$ subjective parameters, Not Relieved: Relief in $<3$ subjective parameters.

\section{Secondary outcome measure}

Relieved: if vas score $<4$ and SF-12 score $>800$, Not Relieved: if vas score $>4$ and / or SF-12 score $<800$

\section{Statistical analysis}

Descriptive and inferential statistical analysis has been carried out in the present study. Results on continuous measurements are presented on the mean $\pm \mathrm{SD}(\min -\max )$ and results on categorical measurements are presented in number (\%). Significance is assessed at $5 \%$ level of significance. The Statistical software namely SPSS 22.0, and R environment ver.3.2.2 were used for the analysis of the data ( Table 1,2).

\section{RESULTS AND DISCUSSION}

\section{Baseline characteristics}

Age: The study participants were similar in both groups concerning baseline characteristics like age, marital status, socioeconomic status, BMI, diet, lifestyle and temperament with $\mathrm{p}>0.05$ (Table 01 ).

Socio-economic status: In present study maximum number of patients, $22(52.4 \%)$ belongs to the lower middle class, $17(40.5 \%), 2$ (4.8\%) and 1 (2.4\%) belongs to upper-middle, upper and lower class respectively. (Table 01) This is similar with the reports of Rehman et al.29 in which $18(40 \%)$ belong to lower middle, 14 (33.35\%), 10 (20\%), 3(6.7\%) upper middle, upper lower and upper class respectively. 
Marital status: In the present study 25(59.5\%) patients were unmarried and 17(40.5\%) were married. (Table 01)

BMI: In present study majority of the patients $23(54.8 \%)$ had normal BMI, followed by $10(23.8 \%), 8(19 \%)$ and 1 $(2.4 \%)$ were overweight, underweight and obese respectively (Table 01) Mean + SD of BMI was 22.38+3.38. (Table 01)

Table 1: Baseline characteristics in two groups studied

$\begin{array}{lcccc}\text { Variables } & \text { Test } & \text { Control } & \text { Total } & \text { P value } \\ & \begin{array}{c}\text { Group } \\ (\mathbf{n}=\mathbf{2 9})\end{array} & \begin{array}{c}\text { Group } \\ (\mathrm{n}=13)\end{array} & \\ & & & \end{array}$

Age in years

\begin{tabular}{lcccc} 
- $18-25$ & $17(58.6 \%)$ & $9(69.2 \%)$ & $26(61.9 \%)$ & 0.513 \\
- $25-35$ & $12(41.4 \%)$ & $4(30.8 \%)$ & $16(38.1 \%)$ & \\
Marital Status & & & & \\
- Married & $13(44.8 \%)$ & $4(30.8 \%)$ & $17(40.5 \%)$ & 0.391 \\
- Unmarried & $16(55.2 \%)$ & $9(69.2 \%)$ & $25(59.5 \%)$ & \\
Socio Economic Status & & & \\
- I & $1(3.4 \%)$ & $1(7.7 \%)$ & $2(4.8 \%)$ & 0.306 \\
- II & $14(48.3 \%)$ & $3(23.1 \%)$ & $17(40.5 \%)$ & \\
- III & $13(44.8 \%)$ & $9(69.2 \%)$ & $22(52.4 \%)$ & \\
- IV & $1(3.4 \%)$ & $0(0 \%)$ & $1(2.4 \%)$ & \\
Diet & & & & \\
- Veg & $7(24.1 \%)$ & $3(23 \%)$ & $10(23.8 \%)$ & 0.150 \\
- Mixed & $22(75.8 \%)$ & $10(76.92 \%)$ & $32(76.2 \%)$ & \\
BMI (kg/m II $^{2}$ & & & & \\
- $\quad<18.5$ & $5(17.2 \%)$ & $3(23.1 \%)$ & $8(19 \%)$ & $0.049^{*}$ \\
- $\quad 18.5-24.9$ & $13(44.8 \%)$ & $10(76.9 \%)$ & $23(54.8 \%)$ & \\
- $\quad 25-29.9$ & $10(34.5 \%)$ & $0(0 \%)$ & $10(23.8 \%)$ & \\
- $>30$ & $1(3.4 \%)$ & $0(0 \%)$ & $1(2.4 \%)$ & \\
Mean \pm SD & $23.20 \pm 4.19$ & $21.57 \pm 2.58$ & $22.69 \pm 3.81$ & 0.204 \\
\hline
\end{tabular}

The test used: Chi-Square/Fisher Exact Test

Table 2: Associated symptoms of dysmenorrhea in two groups studied

\begin{tabular}{lcccc} 
Variables & $\begin{array}{c}\text { Test } \\
\text { Group } \\
(\mathbf{n = 2 9})\end{array}$ & $\begin{array}{c}\text { Control } \\
\text { Group } \\
(\mathbf{n}=13)\end{array}$ & $\begin{array}{c}\text { Total } \\
(\mathbf{n}=42)\end{array}$ & P-value \\
Nausea & $29(100 \%)$ & $12(92.3 \%)$ & $41(97.6 \%)$ & 0.310 \\
Vomiting & $16(55.2 \%)$ & $5(38.5 \%)$ & $21(50 \%)$ & 0.317 \\
LBA & $29(100 \%)$ & $13(100 \%)$ & $42(100 \%)$ & 1.000 \\
Diarrhea & $11(37.9 \%)$ & $4(30.8 \%)$ & $15(35.7 \%)$ & 0.654 \\
Fatigue & $27(93.1 \%)$ & $10(76.9 \%)$ & $37(88.1 \%)$ & 0.162 \\
Bloating & $0(0 \%)$ & $0(0 \%)$ & $0(0 \%)$ & 1.000 \\
$\begin{array}{l}\text { Breast Ten- } \\
\text { derness }\end{array}$ & $7(24.1 \%)$ & $0(0 \%)$ & $7(16.7 \%)$ & $0.079+$ \\
\hline
\end{tabular}

The test used: Chi-square/Fisher Exact Test

\section{Effect of family history and parity}

In present study $38(90.5 \%)$ patients had a positive family history of dysmenorrhoea (Table 03) Similar findings were reported by Tabri N M et al. ${ }^{37}$ and Rehman et al., ${ }^{29}$ wherein the family history was present in $74 \%$ and $63.33 \%$ respectively.

In present study $30(71.4 \%)$ of the patients were nulliparous (26 of these were unmarried and 4 were married), 8 (19\%) of the participants had a history of 2 live births and $4(9.5 \%)$ had more than 2 live births (Table 03 ) the results are consistent with the study conducted by Fletcher et al. ${ }^{116}$ wherein the majority of the patients $88 \%$ are nulliparous and only $7 \%$ were parous.

Table 3: Significant history in two groups studied

\begin{tabular}{lcccc} 
Variables & $\begin{array}{c}\text { Test Group } \\
(\mathbf{n}=\mathbf{2 9})\end{array}$ & $\begin{array}{c}\text { Control } \\
\text { Group } \\
(\mathbf{n}=\mathbf{1 3})\end{array}$ & $\begin{array}{c}\text { Total } \\
(\mathbf{n}=\mathbf{4 2})\end{array}$ & P value \\
Family history & & & & \\
- Present & $25(86.2 \%)$ & $13(100)$ & $38(90.5 \%)$ & 0.258 \\
- Absent & $4(13.8 \%)$ & $0(0 \%)$ & $4(9.5 \%)$ & \\
Parity & & & & \\
- NA & $17(58.6 \%)$ & $9(69.2 \%)$ & $26(61.9 \%)$ & \\
- $0-2$ & $9(31 \%)$ & $3(23.1 \%)$ & $12(54.1 \%)$ & 1.000 \\
- $3-5$ & $3(10.3 \%)$ & $1(7.7 \%)$ & $4(9.5 \%)$ & \\
\hline
\end{tabular}

Test used: Chi-Square/Fisher Exact Test

\section{Pain in abdomen}

All the patients in both the test and control group had pain in abdomen before treatment. In the $1^{\text {st }}$ cycle $2(6.9 \%)$ and $3(23.1 \%)$ had no pain in the abdomen while $27(93.1 \%)$ of patients in the test group and $10(76.9 \%)$ of the patients in the control group had no relief; while In the $2^{\text {nd }}$ cycle $20(69 \%)$ in the test and $13(100 \%)$ in the control group were relieved of pain only $9(31 \%)$ of the patients in the test group had pain in the abdomen. In the after-treatment cycle, $6(20.7 \%)$ and $3(23.1 \%)$ had no pain in the abdomen while in $23(79.3 \%)$ in the test and $10(76.9 \%)$ in control group pain reoccurred. The test group showed improvement of $20.75 \%$ at after treatment, $\mathrm{p}=0.005$ and control group showed improvement of $23.71 \%$ at after treatment, $\mathrm{p}=0.036$, considered significant. On intergroup comparison, w.r.t test group was not significant with $p=1.000$, suggesting that the test drug is as effective as the control in alleviating dysmenorrhea (Table 04).

\section{Nausea}

All the 29(100\%) patients in the test group and 12 (92.3\%) patients in the control group had nausea before treatment. In the $1^{\text {st }}$ cycle, $17(58.6 \%)$ and $13(100 \%)$ patients in the test and control group respectively were relieved of nausea while $12(41.4 \%)$ of patients in the test group had no relief; 
while in the $2^{\text {nd }}$ cycle $28(96.6 \%)$ patients in the test and 13 $(100 \%)$ in the control group were relieved of nausea and only $1(3.4 \%)$ of the patients in the test group had nausea. In the after-treatment cycle, nausea was absent in all patients in the test group and $11(84.6 \%)$ in the control group; while in 2 (15.4\%) patients in control group, nausea reoccurred. The test group showed improvement of $100.00 \%$ at after treatment, $\mathrm{p}<0.001$ and the control group showed improvement of $76.9 \%$ at after treatment, $\mathrm{p}=0.036$, considered significant. On intergroup comparison, w.r.t test group showed suggestive significance with $p=0.091$, suggesting that the test drug is as effective as or more superior to control in alleviating associated with dysmenorrhea (Table 04).

\section{Vomiting}

In present study vomiting was present in $15(51.7 \%)$ patients in the test group and 5(38.5\%) in control group before treatment. In the $1^{\text {st }}$ cycle $23(79.3 \%)$ of patients in the test and 13 $(100 \%)$ of patients in the control group had relieved of vomiting; in the $2^{\text {nd }}$ cycle during treatment and the after-treatment cycle all the patients $29(100 \%)$ and $13(100 \%)$ in the test and control group respectively were relieved of vomiting. The test group showed improvement of $51.7 \%$ with $\mathrm{p}<0.001$ and control group with $38.5 \%$ with $\mathrm{p}=0.137$ considered notsignificant. On intergroup comparison w.r.t test group was not significant with $\mathrm{p}=1.000$, suggesting that the test drug is as effective as the control in alleviating vomiting associated with dysmenorrhea (Table 04)

\section{LBA}

All the patients in both the test and control group had LBA before treatment. In the $1^{\text {st }}$ cycle $10(34.5 \%)$ and $12(92.3 \%)$ patients were relieved of LBA, while $19(65.5 \%)$ of patients in the test group and $1(7.7 \%)$ of the patients in the control group had no relief. In the $2^{\text {nd }}$ cycle, $22(75.9 \%)$ in the test and $13(100 \%)$ in the control group were relieved of LBA and only 7 (24.1\%) of the patients in the test group had LBA. In the after-treatment cycle, $19(65.5 \%)$ and $11(84.6 \%)$ had no LBA, while in $10(34.5 \%)$ in the test and $2(15.4 \%)$ in control group LBA reoccurred. The test group showed improvement of $65.5 \%$, with $\mathrm{p}<0.001$, considered highly sig- nificant, while the control group showed improvement of $84.6 \%$ and is statistically not significant with $\mathrm{p}=0.137$. On intergroup comparison, w.r.t test group was not significant with $\mathrm{p}=1.000$, suggesting that the test drug is as effective as the control in alleviating LBA associated with dysmenorrhea (Table 04).

\section{Diarrhoea}

In the present study, diarrhoea was present in $12(41.5 \%)$ patients in the test group and $4(30.8 \%)$ in the control group before treatment. In the $1^{\text {st }}$ cycle 27 (93.1\%) patients in the test and $13(100 \%)$ patients in the control group had relieved of diarrhoea; in the $2^{\text {nd }}$ cycle during treatment and the aftertreatment cycle all the patients $29(100 \%)$ and $13(100 \%)$ in the test and control group respectively were relieved of diarrhoea. The test group showed improvement of $41.4 \%$, with $\mathrm{p}=0.036$, considered significant; the control group showed improvement of $30.8 \%$ after treatment with $\mathrm{P}=0.137$, statistically not significant. On intergroup comparison w.r.t test group was not significant with $\mathrm{p}=1.000$, suggesting that the test drug is as effective as the control in alleviating diarrhoea associated with dysmenorrhea (Table 4).

\section{Fatigue}

In the present study, fatigue was present in $27(93.1 \%)$ patients in the test group and $10(76.9 \%)$ in the control group before treatment. In the $1^{\text {st }}$ cycle, $14(48.3 \%)$ patients in test and $12(92.3 \%)$ of patients in the control group had relieved of fatigue; in the $2^{\text {nd }}$ cycle, $23(79.3 \%)$ patients in the test group and all the patients of the control group were relieved of fatigue. In the after-treatment cycle, 14 (48.3\%) and 12 $(92.3 \%)$ patients in the test and control group respectively were relived of fatigue while in $15(51.7 \%)$ patients in test and $1(7.7 \%)$ in control group fatigue reoccurred. The test group showed improvement after treatment is $41.4 \%$, with $\mathrm{p}<0.001$, statistically significant. Control group showed improvement at after treatment is $69.2 \%$ is statistically significant with $\mathrm{p}<0.001$ with paired proportion test. On intergroup comparison, w.r.t test group was significant with $\mathrm{p}=0.007$, suggesting that the test drug is inferior to control in alleviating fatigue associated with dysmenorrhea (Table 4).

Table 4: Assessment of subjective parameters

\begin{tabular}{|c|c|c|c|c|c|c|}
\hline Pain in Abdomen & BT & $C_{1}$ & $\mathrm{C}_{2}$ & AT & $\%$ difference & P - value \\
\hline \multicolumn{7}{|l|}{ Test Group $(n=29)$} \\
\hline - Absent & $\mathrm{o}(\mathrm{o} \%)$ & $2(6.9 \%)$ & $20(69 \%)$ & $6(20.7 \%)$ & $20.7 \%$ & 0.005 \\
\hline - Present & $29(100 \%)$ & $27(93.1 \%)$ & $9(31 \%)$ & $23(79 \cdot 3 \%)$ & $-20.7 \%$ & \\
\hline \multicolumn{7}{|c|}{ Control Group $(n=13)$} \\
\hline - Absent & $\mathrm{o}(\mathrm{o} \%)$ & $3(23.1 \%)$ & $13(100 \%)$ & $3(23.1 \%)$ & $23.1 \%$ & 0.0 .036 \\
\hline - Present & $13(100 \%)$ & $10(76.9 \%)$ & $\mathrm{o}(\mathrm{o} \%)$ & $10(76.9 \%)$ & $-23.1 \%$ & \\
\hline Pvalue* & 1.000 & 0.162 & $0.038^{*}$ & 1.000 & - & \\
\hline \multicolumn{7}{|l|}{ Nausea } \\
\hline Test Group $(\mathrm{n}=29)$ & & & & & & \\
\hline
\end{tabular}


Table 4: (Continued)

\begin{tabular}{|c|c|c|c|c|c|c|}
\hline Pain in Abdomen & BT & $C_{1}$ & $\mathrm{C}_{2}$ & AT & $\%$ difference & P - value \\
\hline Absent & $\mathrm{o}(\mathrm{o} \%)$ & $17(58.6 \%)$ & $28(96.6 \%)$ & $29(100 \%)$ & $100.0 \%$ & $<0.001$ \\
\hline Present & $29(100 \%)$ & $12(41.4 \%)$ & $1(3.4 \%)$ & $\mathrm{o}(\mathrm{o} \%)$ & $-100.0 \%$ & \\
\hline \multicolumn{7}{|c|}{ Control Group $(n=13)$} \\
\hline Absent & $1(7 \cdot 7 \%)$ & $13(100 \%)$ & $13(100 \%)$ & ${ }_{11}(84.6 \%)$ & $76.9 \%$ & 0.036 \\
\hline Present & $12(92.3 \%)$ & $\mathrm{o}(\mathrm{o} \%)$ & $\mathrm{o}(\mathrm{o} \%)$ & $2(15 \cdot 4 \%)$ & $-76.9 \%$ & \\
\hline Pvalue* & 0.310 & $0.008^{* *}$ & 1.000 & $0.091+$ & - & \\
\hline \multicolumn{7}{|l|}{ Vomiting } \\
\hline \multicolumn{7}{|l|}{ Test Group $(n=29)$} \\
\hline Absent & $14(48.3 \%)$ & $23(79 \cdot 3 \%)$ & $29(100 \%)$ & $29(100 \%)$ & $51.7 \%$ & 0.001 \\
\hline Present & $15(51.7 \%)$ & $6(20.7 \%)$ & $\mathrm{o}(\mathrm{o} \%)$ & $\mathrm{o}(\mathrm{o} \%)$ & $-51.7 \%$ & \\
\hline \multicolumn{7}{|c|}{ Control Group $(n=13)$} \\
\hline Absent & $8(61.5 \%)$ & $13(100 \%)$ & $13(100 \%)$ & $13(100 \%)$ & $38.5 \%$ & 0.137 \\
\hline Present & $5(38.5 \%)$ & $\mathrm{o}(\mathrm{o} \%)$ & $\mathrm{o}(\mathrm{o} \%)$ & $\mathrm{o}(\mathrm{o} \%)$ & $-38.5 \%$ & \\
\hline Pvalue* $^{*}$ & 0.426 & 0.153 & 1.000 & 1.000 & - & \\
\hline \multicolumn{7}{|l|}{$\begin{array}{l}\text { LBA } \\
\text { Test Group }(n=29)\end{array}$} \\
\hline Absent & $\mathrm{o}(\mathrm{o} \%)$ & $10(34.5 \%)$ & $22(75 \cdot 9 \%)$ & $19(65.5 \%)$ & 65.55 & $<0.001$ \\
\hline Present & $29(100 \%)$ & $19(65 \cdot 5 \%)$ & $7(24.1 \%)$ & $10(34.5 \%)$ & $-65 \cdot 5 \%$ & \\
\hline \multicolumn{7}{|c|}{ Control Group $(n=13)$} \\
\hline Absent & $\mathrm{o}(\mathrm{o} \%)$ & $12(92.3 \%)$ & $13(100 \%)$ & ${ }_{11}(84.6 \%)$ & $84.6 \%$ & 0.137 \\
\hline Present & $13(100 \%)$ & $1(7.7 \%)$ & $\mathrm{o}(\mathrm{o} \%)$ & $2(15.4 \%)$ & $-84.6 \%$ & \\
\hline Pvalue* & 1.000 & $0.001^{* *}$ & $0.079+$ & 0.282 & & \\
\hline \multicolumn{7}{|l|}{ Diarrhoea } \\
\hline \multicolumn{7}{|l|}{ Test Group $(n=29)$} \\
\hline Absent & $17(58.6 \%)$ & $27(93.1 \%)$ & $29(100 \%)$ & $29(100 \%)$ & $41.4 \%$ & 0.036 \\
\hline Present & $12(41.4 \%)$ & $2(6.9 \%)$ & $\mathrm{o}(\mathrm{o} \%)$ & $\mathrm{o}(\mathrm{o} \%)$ & $-41.4 \%$ & \\
\hline \multicolumn{7}{|c|}{ Control Group $(n=13)$} \\
\hline Absent & $9(69.2 \%)$ & $13(100 \%)$ & $13(100 \%)$ & $13(100 \%)$ & $30.8 \%$ & 0.137 \\
\hline Present & $4(30.8 \%)$ & $\mathrm{o}(\mathrm{o} \%)$ & $\mathrm{o}(\mathrm{o} \%)$ & $\mathrm{o}(\mathrm{o} \%)$ & $-30.8 \%$ & \\
\hline Pvalue* & 0.513 & 1.000 & 1.000 & 1.000 & - & \\
\hline \multicolumn{7}{|l|}{ Fatigue } \\
\hline \multicolumn{7}{|l|}{ Test Group $(n=29)$} \\
\hline Absent & $2(6.9 \%)$ & $14(48.3 \%)$ & $23(79 \cdot 3 \%)$ & $14(48.3 \%)$ & $41.4 \%$ & $<0.001$ \\
\hline Present & $27(93.1 \%)$ & $15(51.7 \%)$ & $6(20.7 \%)$ & $15(51.7 \%)$ & $-41.4 \%$ & \\
\hline \multicolumn{7}{|c|}{ Control Group $(n=13)$} \\
\hline Absent & $3(23.1 \%)$ & $12(92.3 \%)$ & $13(100 \%)$ & $12(92.3 \%)$ & $69.2 \%$ & $<0.001$ \\
\hline Present & $10(76.9 \%)$ & $1(7 \cdot 7 \%)$ & $\mathrm{o}(\mathrm{o} \%)$ & $1(7 \cdot 7 \%)$ & $-69.2 \%$ & \\
\hline Pvalue* & 0.162 & $0.007^{* *}$ & 0.153 & $0.007^{* *}$ & - & \\
\hline
\end{tabular}

Test used: * Chi-Square/Fisher Exact Test and ${ }^{* *}$ Paired Proportion test

\section{VAS Score}

Mean \pm SD of test group before treatment $1^{\text {st }}$ cycle, $2^{\text {nd }} c y-$ cle and after treatment are $9.03 \pm 0.73,4.90 \pm 1.11,1.79 \pm 1.61$ and $3.14 \pm 1.30$ respectively, there was a statistically significant decrease in VAS score with p-value $<0.001$ in the first cycle and continued till after treatment cycle with $\mathrm{p}<$ 0.001 , considered highly significant. Similarly, in control group mean \pm SD before treatment $1^{\text {st }}$ cycle, $2^{\text {nd }}$ cycle and after treatment are $8.77 \pm 0.93,3.23 \pm 1.59,0.00 \pm 0.00$ and $2.77 \pm 1.64$ respectively, there was a statistically significant decrease in VAS score with p-value $<0.001$ in the first cycle and continued till after treatment cycle with $\mathrm{p}<0.001$, considered highly significant. The intergroup comparison w.r.t test group after treatment there was no significant difference with $\mathrm{p}=0.439$; suggesting that test drug is as effective as the control in improving the VAS scores in dysmenorrhea (Table 05). The effect of the test drug on VAS score in the present study is comparable with the studies conducted by Kannan $\mathrm{P}$ et al. ${ }^{34}$ with treadmill exercise, Azima $\mathrm{S}$ et al. ${ }^{21}$ with massage therapy and exercise, Harada et al. ${ }^{35}$ using low dose oral contraceptives, Molins Cubero et al. ${ }^{23}$ evaluating pain perception after pelvis manipulation, Mingxio et al. ${ }^{13}$ with moxibustion, Molouk et al. ${ }^{20}$ with cinnamon, Yasemin et $a l .{ }^{36}$ with the intervention of diet, Rehman et al. ${ }^{29}$ using Rheum emodi, Asma et al. ${ }^{22}$ with Ferula asafoetida showed similar outcome with $\mathrm{p}=<0.001$. 
Table 5: VAS score- A comparison in two groups of patients studied

\begin{tabular}{lcccc} 
VAS score & Test Group & $\begin{array}{c}\text { Control } \\
\text { Group }\end{array}$ & Total & P-value \\
RESULTS & & & \\
- BT & $9.03 \pm 0.73$ & $8.77 \pm 0.93$ & $8.95 \pm 0.79$ & 0.323 \\
- & $4.90 \pm 1.11$ & $3.23 \pm 1.59$ & $4.38 \pm 1.48$ & $<0.001^{* *}$ \\
- C2 & $1.79 \pm 1.61$ & $0.00 \pm 0.00$ & $1.24 \pm 1.57$ & $<0.001^{* *}$ \\
- AT & $3.14 \pm 1.30$ & $2.77 \pm 1.64$ & $3.02 \pm 1.41$ & 0.439 \\
P VALUE BT & & & & \\
- C1 & $<0.001^{* *}$ & $<0.001^{* *}$ & $<0.001^{* *}$ & - \\
- C2 & $<0.001^{* *}$ & $<0.001^{* *}$ & $<0.001^{* *}$ & - \\
- AT & $<0.001^{* *}$ & $<0.001^{* *}$ & $<0.001^{* *}$ & - \\
\hline
\end{tabular}

The test used: Student t-test

\section{SF-12}

Mean \pm SD of test group before and after treatment were $523.45 \pm 65.82$ and $986.03 \pm 99.95$ respectively with $p$-value $<0.001$, considered highly significant. Similarly, in control group mean \pm SD before treatment and after treatment were $513.08 \pm 60.91$ and $1034.62+31.61$ respectively with p-value $<0.001$ and it is considered highly significant. The intergroup comparison concerning test group after treatment was not significant with $\mathrm{p}>0.05$ suggesting that test formulation is as effective as the control in improving the quality of life in patients with dysmenorrhea (Table 06). The effect of test drug on quality of life is similar to that found in studies of Kannan $\mathrm{P}$ et al. ${ }^{33}$ Rehman et al. ${ }^{29}$ and Asma et al. ${ }^{22}$ with significant improvement in each study with $\mathrm{p}<0.01$.

Table 6: SF-12-A comparison in two groups of patients studied

\begin{tabular}{lcccc} 
SF-12 & Test Group & $\begin{array}{c}\text { Control } \\
\text { Group }\end{array}$ & Total & $\begin{array}{c}\text { P- } \\
\text { value }\end{array}$ \\
BT & $523.45 \pm 65.82$ & $513.08 \pm 60.91$ & $520.24 \pm 63.78$ & 0.632 \\
AT & $986.03 \pm 99.95$ & $1034.62 \pm 39.61$ & $1001.07 \pm 88.31$ & 0.100 \\
P value & $<$ o.oo1 $^{* *}$ & $<0.001^{* *}$ & $<0.001^{* *}$ & - \\
\hline
\end{tabular}

The test used: Student t-test

\section{Primary outcome measure}

In the present study, $26(89.7 \%)$ of the patients in the test group and $13(100 \%)$ in the control group were relieved. Statistical analysis shows no significant difference $(p=1.00)$ in alleviating subjective parameters in two groups of patients studied, suggesting that test drug is as effective as control (Table 07)

\section{Secondary outcome measure}

In the present study, $26(89.7 \%)$ of the patients in the test group and $13(100 \%)$ in the control group were relieved. Statistical analysis shows no significant difference $(\mathrm{p}=0.540)$ in improving objective parameters in two groups of patients studied, suggesting that test drug is as effective as control (Table 07)

\begin{tabular}{|c|c|c|c|c|}
\hline Outcome measure & Relieved & $\begin{array}{l}\text { Not Re- } \\
\text { lieved }\end{array}$ & Total & P-value \\
\hline $\begin{array}{l}\text { Primary outcome } \\
\text { measure (POM) } \\
\text { Test group }\end{array}$ & 89.7 & 10.3 & 90.5 & 1 \\
\hline $\begin{array}{l}\text { Primary outcome } \\
\text { measure (POM) } \\
\text { Control group }\end{array}$ & 100 & o & 7.1 & $<0.001^{* *}$ \\
\hline $\begin{array}{l}\text { Secondary outcome } \\
\text { measure: } \\
\text { (SOM) Test group }\end{array}$ & 89.7 & 10.3 & 92.9 & 0.54 \\
\hline $\begin{array}{l}\text { Secondary outcome } \\
\text { measure: } \\
\text { (SOM) Control } \\
\text { group }\end{array}$ & 100 & o & 7.1 & $<0.001^{* *}$ \\
\hline
\end{tabular}

Test used: Chi-Square/Fisher Exact Test

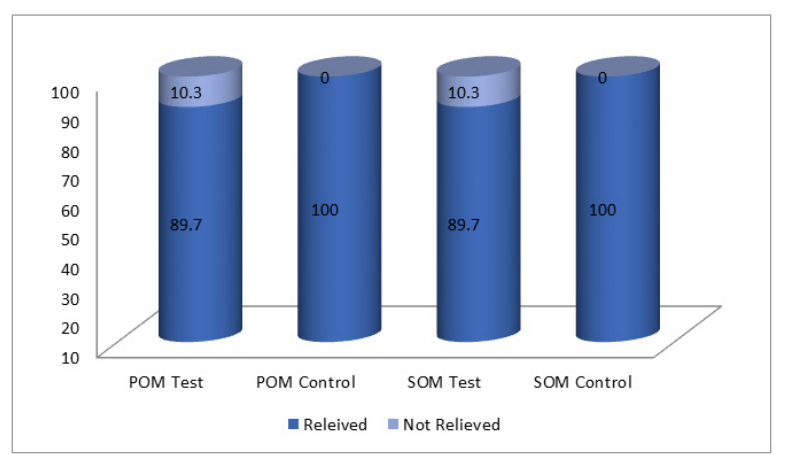

Limitations of this study are small sample size, validated scales for assessment of subjective parameters not used, differentiation of patients having primary or secondary dysmenorrhea was not done because of lack of basic investigations like USG. We recommend that studies with a larger sample size should be considered. Minimal investigations like USG pelvis should be done to differentiate the primary and secondary dysmenorrhea, and the effect of test drug on dysmenorrhea associated with different pathologies can be studied. Validated scales for assessment of subjective parameters should be incorporated.

\section{CONCLUSION}

The findings from the present study demonstrated that majoon murmakki is as effective as mefenamic acid in the management of usr tamth (dysmenorrhea). The effect of majoonmurmakkion usrtamth (dysmenorrhea) may be attributed to its properties like musakkinawjāh (analgesic), muhallilawrām (anti-inflammatory), mudirr-i-bawlwahayd 
(diuretic and emmenagogue), muffattih-i-sudad (deobstruent) among others; also analgesic activity of furanosesquiterpenes such as furanoelemanes, furanoeudes-manes and furanogermacranes present in the gum resin extract of myrrh. Hence, Majoon murmakki is a safe, herbal therapeutic option that can provide an alternate management option with no adverse events as caused by conventional treatments in usrtamth (dysmenorrhea).

\section{ACKNOWLEDGEMENT}

Authors acknowledge the immense help received from the scholars whose articles are cited and included in references of this manuscript. The authors are also grateful to authors / editors / publishers of all those articles, journals and books from where the literature for this article has been reviewed and discussed.

\section{Conflict of interest: None}

Financial support: National Institute of Unani Medicine

\section{REFERENCES}

1. Mittal R. Medical management of dysmenorrhea. Int J Adv Res Ideas Innov Tech 2019; 5(1): 5-8.

2. Gebeyehu MB, Mekuria AB, Tefera YG, Andarge DA, Debay YB, Bejiga GS, et al. Prevalence, impact, and management practice of dysmenorrhea among university of Gondar students, northwestern Ethiopia: a cross-sectional study. Int J Reprod Med 2017; 2017:1-8.

3. Franjic S. Menstrual pain. J Gynecol Res Obstet 2019; 5(2): 31 33.

4. De Sanctis V, Soliman A, Bernasconi S, Bianchin L, Bona G, Bozzola M. Definition and self-reported pain intensity in adolescents with dysmenorrhea: A debate report. Rivista Italiana di Medicinadell' Adolescenza. 2016;14(2):5-11.

5. Mohapatra D, Mishra TA, Behera M, Panda PR. A study of relation between body mass index and dysmenorrhea and its impact on daily activities of medical students. Asian J Pharm Clin Res 2016;9(3):297-9.

6. Chen CX, Barrett B, Kwekkeboom KL. Efficacy of oral ginger (Zingiber officinale) for dysmenorrhea: a systematic review and meta-analysis. Evid Based Complem Altern Med 2016; 2016:110.

7. Razi AMZ. Kitab- al- hawi. Vol -IX. New Delhi: CCRUM;2001.

8. Arzani MA. Qarabadeen qadri. New Delhi: CCRUM;2009.

9. Khan MA, Kabeeruddin M. Akseereazam (Al-akseer), NewDelhi: Idarae Kitab-ul-shifa; 2011.

10. Rafiquddin M. Kanzul adviae mufrada. Aligarh: University Publication Unit: sarfraz house AMU; 1985.

11. Germano A, Occhipinti A, Barbero F, Maffei ME. A pilot study on bioactive constituents and analgesic effects of Myrliq, a Commiphora myrrha extract with a high furanodiene content. BioMed Res Int 2017; 2017:1-11.

12. Sakpal TV. Sample size estimation in a clinical trial. Perspec Clin Res 2010; 1(2):67-69.

13. Yang M, Chen X, Bo L, Lao L, Chen J, Yu S, et al. Moxibustion for pain relief in patients with primary dysmenorrhea: A randomized controlled trail. PLoS One. 2017; 12(2): e0170952.
14. Rahnama P, Montazeri A, Huseini HF, Kianbakht S, Naseri M. Effect of Zingiber officinale R. rhizomes(ginger) on pain relief in primary dysmenorrhea: a placebo randomized trial. BMC Complement Altern Med 2012; 12:92.

15. Nahid K, Fariborz M, Ataolah G, Solokian S. The effect of an Iranian herbal drug on primary dysmenorrhea: a clinical controlled trial. J Midwifery Women's Health 2009;54(5):401-4.

16. Salmalian H, Saghebi R, Moghadamnia AA, Bijani A, Faramarzi M, Amiri FN, et al. Comparative effect of thymus Vulgaris and ibuprofen on primary dysmenorrhea: A triple-blind clinical study. Casp J Intern Med 2014;5(2):82.

17. Liu CZ, Xie JP, Wang LP, Liu YQ, Song JS, Chen YY, et al. A randomized controlled trial of single point acupuncture in primary dysmenorrhea. Pain Med 2014;15(6):910-20.

18. Shirvani MA, Motahari-Tabari N, Alipour A. The effect of mefenamic acid and ginger on pain relief in primary dysmenorrhea: a randomized clinical trial. Archiv Gynecol Obste 2015;291(6):1277-81.

19. Han SH, Hur MH, Buckle J, Choi J, Lee MS. Effect of aromatherapy on symptoms of dysmenorrhea in college students: A randomized placebo-controlled clinical trial. J Altern Complement Med 2006;12(6):535-41.

20. Jaafarpour M, Hatefi M, Khani A, Khajavikhan J. Comparative effect of cinnamon and ibuprofen for treatment of primary dysmenorrhea: a randomized double-blind clinical trial. JCDR 2015;9(4): 4-7.

21. Azima S, Bakhshayesh HR, Kaviani M, Abbasnia K, Sayadi M. Comparison of the effect of massage therapy and isometric exercises on primary dysmenorrhea: a randomized controlled clinical trial. J Pediatr Adolesc Gynecol 2015;28(6):486-91.

22. Asma K, Sultana A, Rahman K. A single-blind randomized comparative study of asafoetida vs mefenamic acid in dysmenorrhea, associated symptoms and health-related quality of life. J Herb Med 2017; 9:21-31.

23. Molins-Cubero S, Rodríguez-Blanco C, Oliva-Pascual-Vaca Á, Heredia-Rizo AM, Boscá-Gandía JJ, Ricard F. Changes in pain perception after pelvis manipulation in women with primary dysmenorrhea: a randomized controlled trial. Pain Med 2014;15(9):1455-63.

24. Mannix LK, Martin VT, Cady RK, Diamond ML, Lener SE, White JD, et al. Combination treatment for menstrual migraine and dysmenorrhea using sumatriptan-naproxen: two randomized controlled trials. Obstetr Gynecol 2009;114(1):106-13.

25. Morrison BW, Daniels SE, Kotey P, Cantu N, Seidenberg B. Rofecoxib, a specific cyclooxygenase-2 inhibitor, in primary dysmenorrhea: a randomized controlled trial. Obstetri Gynecol 1999;94(4):504-8.

26. Chiu MH, Hsieh HF, Yang YH, Chen HM, Hsu SC, Wang HH. Influencing factors of dysmenorrhoea among hospital nurses: a questionnaire survey in Taiwan. BMJ 2017;7(12):1-8.

27. Malmstrom K, Kotey P, Cichanowitz N, Daniels S, Desjardins PJ. Analgesic efficacy of etoricoxib in primary dysmenorrhea: results of a randomized, controlled trial. Gynecol Obstetr Investig 2003;56(2):65-9.

28. Atallahi M, Akbari SA, Mojab F, Majd HA. Effects of wheat germ extract on the severity and systemic symptoms of primary dysmenorrhea: a randomized controlled clinical trial. Iranian Red Crescent Med J 2014; 16(8):1-7.

29. Rehman H, Begum W, Anjum F, Tabasum H, Zahid S. Effect of rhubarb (Rheum emodi) in primary dysmenorrhoea: a singleblind randomized controlled trial. J Complement Integr Med 2015;12(1):61-9.

30. Motahari-Tabari N, Shirvani MA, Alipour A. Comparison of the effect of stretching exercises and mefenamic acid on the reduc- 
tion of pain and menstruation characteristics in primary dysmenorrhea: a randomized clinical trial. Oman Med J 2017;32(1):47.

31. Shaviv H, Rosen DJ, Ezra Y. Dysmenorrhea: A randomized controlled clinical trial evaluating a novel treatment approach. Cogent Med 2018; 5 (1): 1-12.

32. Fletcher HM, Dawkins J, Rattray C, Wharfe G, Reid M, Gordon-Strachan G. Morinda citrifolia (Noni) as an anti-inflammatory treatment in women with primary dysmenorrhoea: a randomised double-blind placebo-controlled trial. Obstetr Gynecol Int 2013;2013:1-6.

33. Uysal G, Akkaya H, Cagli F, Tutus S, Tayyar AT. A comparison of two different oral contraceptives in patients with severe primary dysmenorrhoea. J Obstetr Gynaecol 2018;38(6):828-32.
34. Kannan P, Chapple CM, Miller D, Claydon-Mueller L, Baxter GD. Effectiveness of a treadmill-based aerobic exercise intervention on pain, daily functioning, and quality of life in women with primary dysmenorrhea: A randomized controlled trial. Contemp Clin Trials 2019; 81:80-6.

35. Harada T, Momoeda M, Terakawa N, Taketani Y, Hoshiai H. Evaluation of a low- dose oral contraceptive pill for primary dysmenorrhea: a placebo-controlled, double-blind, randomized trial. Fertility Sterility 2011;95(6):1928-31.

36. Kartal YA, Akyuz EY. The effect of diet on primary dysmenorrhea in university students: A randomized controlled clinical trial. PJMS 2018; 34(6): 1478-82. 